\title{
Perbandingan Penggunaan Grip Karet Dan Towel Terhadap Tingkat Kenyamanan Siswa Dalam Permainan Bulutangkis Siswa Kelas X MAN 2 Banyuwangi Tahun Ajaran 2018/2019
}

\author{
Muhammad Farid ${ }^{1}$, Donny Setiawan², Arya T Candra ${ }^{3}$ \\ 1,2,3Fakultas Olahraga dan Kesehatan \\ 1,2,3Universitas PGRI Banyuwangi \\ Email: faridm0507@gmail.com
}

\begin{abstract}
ABSTRAK
Raket merupakan alat yang digunakan pemain dalam bulutangkis. Kenyamanan raket akan mempengarui permainan seseorang sehingga mereka memilih jenis pegangan yang digunakan seperti karet dan towel. Penelitian ini merupakan penelitian kuantitatif dengan metode pengambilan data menggunakan angket untuk mengetahui tingkat kenyamanan pegangan. Variabel dalam penelitian ini adalah bahan pegangan raket yaitu towel dan karet. Subyek penelitian ini adalah siswa kelas X MAN 2 Banyuwangi. Hasil penelitian menunjukkan bahwa prosentase kenyaman pada pegangan raket dengan menggunakan towel sebesar $55,78 \%$ sedangkan pada pegangan raket menggunakan karet sebesar $44,22 \%$. Berdasarkan asil penelitian dapat disimpulkan bahwa jenis towel lebih nyaman dibandingkan jenis karet, karena jenis towel lebih nyaman dipegang dan dapat menyerap keringan. Sedangkan pada jenis karet lebih licin karena tidak dapat menyerap keringat.
\end{abstract}

Kata kunci: towel, karet, raket, bulutangkis

\section{PENDAHULUAN}

Menurut Liem (2014) pendidikan adalah usaha sadar dan terencana secara etis, sistematis, intensional dan kreatif dimana peserta didik mengembangkan potensi diri, kecerdasan, pengendalian diri dan keterampilan untuk membuat dirinya berguna di masyarakat.Menurut Yuli Sectio Rini (2013) pendidikan adalah segala daya upaya dan semua usaha untuk membuat masyarakat dapat mengembangkan potensi peserta didik agar memiliki kekuatan spiritual keagamaan, pengendalian diri, berkepribadian, memiliki kecerdasan, berakhlak mulia, serta memiliki keterampilan yang diperlukan sebagai anggota masyarakat dan warga negara. Jadi dapat kita simpulkan bahwa pendidikan adalah sebuah proses yang dilakukan oleh pendidik terhadap anak didik memberikan bekal pengarahan dan menyiapkan mereka untuk terjun ke masyarakat kelak.

Bulutangkis merupakan olahraga yang sangat populer di Indonesia, dari semua kalangan masyarakat mayoritas mengenal olahraga tersebut dan ikut memainkannya. Menurut Agus Pujianto (2012) baik di kota-kota besar maupun di desa-desa, permainan bulutangkis ini merupakan permainan yang sangat digemari oleh hampir semua lapisan masyarakat, tua, muda, laki-laki, maupun perempuan. Olahraga bulutangkis di Indonesia mengalami perkembangan yang cukup pesat di tiap daerah, kita sering menemui klub - klub yang membina anak (calon atlet) sejak usia dini. Dengan harapan dapat menjadi atlet yang berprestasi dimasa yang akan datang. Menurut Prasetya (2012) selain sebagai olahraga rekreasi, bulutangkis 
merupakan olahraga prestasi yang mampu membawa Indonesia ke prestasi tingkat dunia. Dengan adanya prestasi yang membanggakan itu, maka olahraga bulutangkis tidak lepas dari proses pembinaan dan latihan dengan harapan mampu meraih prestasi di kancah nasional dan internasional.

Selain klub yang dijadikan tempat untuk mengasah para atlet - atlet muda untuk mencapai prestasi, pemerintah sepertinya sadar akan hal itu dan membuat wadah para atlet muda bulutangkis Indonesia sebagai wujud kepedulian masyarakat dan pemerintah. Oleh karena itu mulai muncul wadah wadah yang dikelola langsung oleh Persatuan Bulutangkis Seluruh Indonesia ( PBSI ) yang berwujud sekolah atau diklat yang bertempat di daerah atau kota diseluruh Indonesia. Dengan membidik anak - anak yang berusia sekolah, maka dengan harapan kedepannya nanti bisa menjadi bibit juara serta perkembangan perbulutangkisan Indonesia dimasa yang akan datang.

Anak - anak di berbagai daerah di Indonesia banyak yang menyukai olahraga bulutangkis mulai dari tingkatan pendidikan SD, SMP maupun di tingkat SMA. Di sisi lain masih banyak terdapat ketidak pahaman tentang teknik - teknik permainan bulutangkis, salah satunya seperti penggunaan raket yang kurang baik dan benar yang mengakibatkan gerakan siswa terbatasi dan kurang maksimal. Pujianto (2012) berpendapat bahwa salah satu teknik dasar bulutangkis yang sangat penting dikuasai secara benar oleh setiap calon pebulutangkis adalah pegangan raket (grip). Pegangan raket (grip) merupakan pegangan yang berada di pangkal raket yang terbuat dari dua bahan yaitu towel (handuk) dan karet, berfungsi melindungi tangan agar tidak cidera serta nyaman dalam melakukan pukulan-pukulan dalam permainan bulutangkis.

Ketika akan memilih pegangan raket (grip), kita harus bisa memilih berdasarkan keadaan dari tangan kita sendiri, apakah tangan kita kering atau tangan kita basah. Menurut Jae Hade (2018) grip handuk paling baik untuk telapak tangan yang basah, jika hendak memaksa memakai bahan sintetis pilih yang super tacky feel. Untuk telapak tangan kering, cari yang rasanya cukup lengket saat grip tergenggam dalam telapak tangan. Oleh karena itu pemilihan grip raket sangat berperan penting untuk kenyamanan seseorang dalam bermain bulutangkis.

\section{METODE}

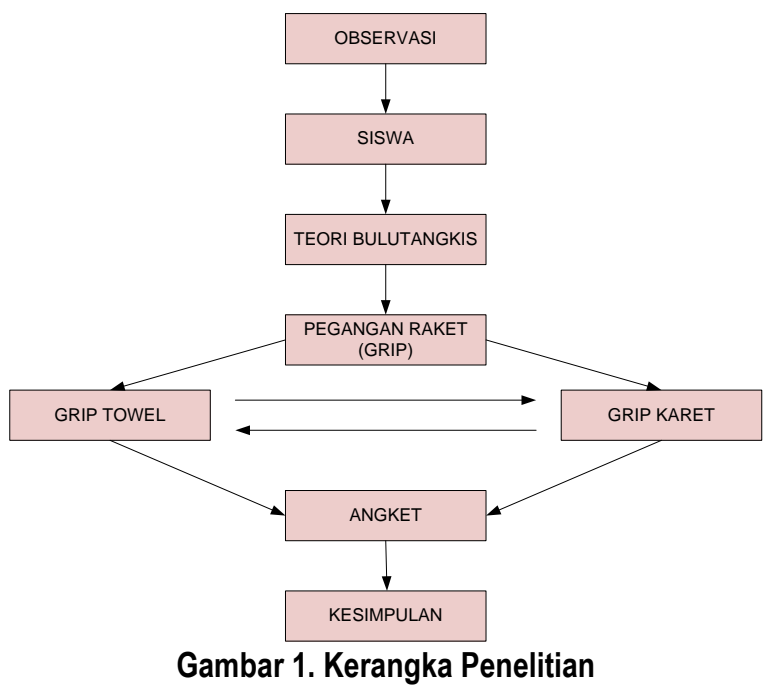


Penelitian dilakukan dengan cara observasi kepada siswa tentang teori bulutangkis. Menjelaskan tentang pegangan pada raket menggunakan towel dan karet. Siswa diberikan angket untuk mengetahui tingkat kenyamanan pegangan raket menggunakan towel dan karet.

Penelitian ini adalah penelitian kuantitatif yang pengambilan datanya dengan cara kuesioner, observasi dan ditambah dengan dokumentasi. Metode penelitian kuantitatif dapat diartikan sebagai metode penelitian yang berlandasan pada filsafat positivisme, digunakan untuk meneliti pada populasi atau sampel tertentu, tehnik pengambilan sampel pada umumnya dilakukan dengan cara random, pengumpulan data menggunakan instrumen penelitian analisis data bersifat kuantitatif atau statistik dengan tujuan untuk menguji hipotesis yang telah ditetapkan (Sugiyono, 2015).

Menurut Sugiyono (2015:207) analisis data merupakan kegiatan setelah data dari seluruh responden atau sumber data lain terkumpul. Analisis data menggunakan teknik analisis deskriptif kuantitatif dengan persentase. Data dianalisis secara deskriptif dengan presentase, sebelumnya akan dikategorikan terlebih dahulu. Adapun langkah-langkah yang digunakan yaitu: (1) menskor jawaban, (2) menjumlah skor jawaban berdasarkan faktor secara keseluruhan, (3) membuat presentase dengan rumus.

Untuk mencari besarnya (presentase) menurut Anas (2012 dalam Rio Dwi Arnanda 2017) dengan rumus sebagai berikut :

$$
\mathrm{P}=\frac{F}{N} \times 100 \%
$$

Keterangan : $\mathrm{P}=$ Angka presentase, $f=$ Frekuensi yang sedang dicari persentasenya, $\mathrm{N}=$ Number of cases (jumlah frekuensi/banyaknya individu).

Jumlah pernyataan pada tes ini berjumlah 30 butir soal. Setiap jawaban yang benar skornya adalah 1 , dan skor untuk jawaban salah adalah 0 . Sehingga skor maksimal jika semua jawaban benar adalah 30 , dan skor minimal jika semua jawaban salah adalah 0 .

\section{HASIL}

\section{Data Hasil Jawaban Responden Pada Penggunaan Grip Towel dan Karet}

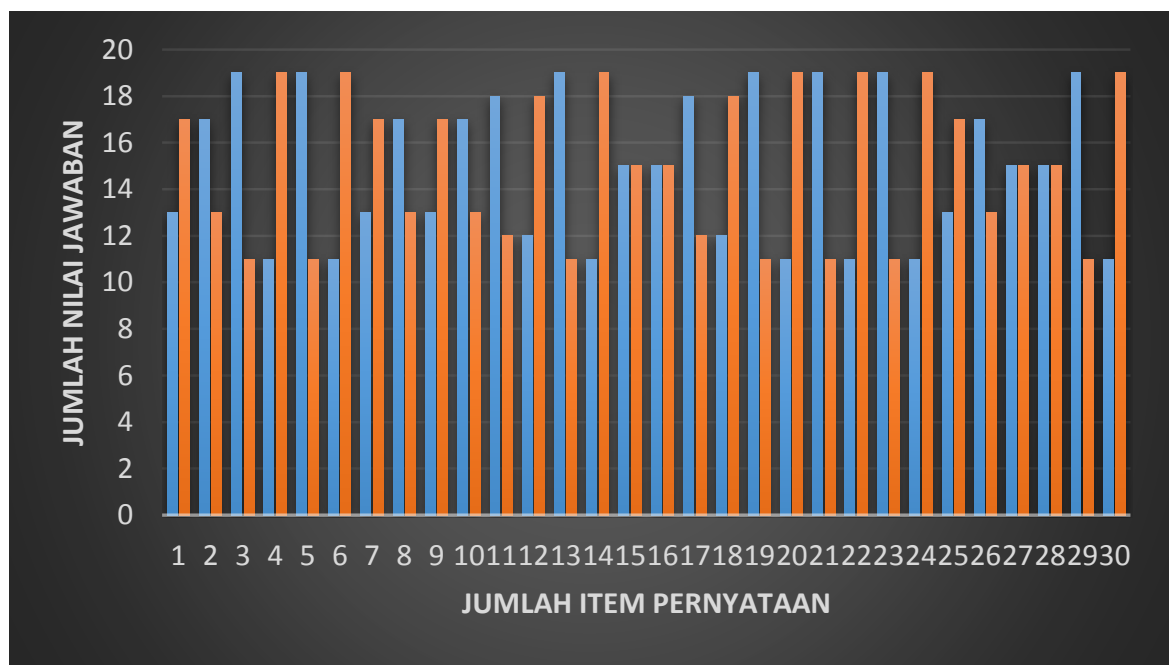

Diagram 1. Hasil Jawaban Responden 
Berdasarkan pada diagram $1 \mathrm{di}$ atas menjelaskan seluruh jawaban peritem pernyataan dari seluruh jumlah responden. bisa dilihat pada nomor 1 dari seluruh responden telah menjawab pernyataan sebanyak 13 untuk variabel towel dan sebanyak 17 untuk pernyataan variabel karet.

\section{Prosentase Hasil Jawaban Responden}

Tabel 1. Hasil Prosentase Jawaban

\begin{tabular}{ccccc}
\hline Subyek & Towel & $\mathbf{P}(\%)$ & Karet & $\mathbf{P}(\%)$ \\
\hline 30 & 8.37 & 55.78 & 6.63 & 44.22 \\
\hline
\end{tabular}

Berdasarkan tabel 1 di atas dapa dijelaskan bahwa dari 30 subyek prosentase grip dengan towel $55,78 \%$ dan prosentase grip dengan karet sebesar $44,22 \%$.

\section{PEMBAHASAN}

Penelitian ini adalah penelitian yang bertujuan untuk membandingkan kenyamanan antara dua variabel yaitu variabel grip karet dan variabel grip towel, yang mana peneliti mengambil sampel dari siswa kelas $\mathrm{X}$ Madrasah Aliyah Negeri 2 Banyuwangi sejumlah 30 responden yang sebelumnya telah dipilih secara kriteria peneliti. Dalam pengambilan data peneliti menggunakan metode kuesioner yang berupa pernyataan sejumlah 30 butir. Kemudian responden diberikan materi terkait grip raket yang dilanjutkan melakukan permaianan bulutangkis menggunakan grip karet dan towel secara bergantian. Setelah responden selesai bermaian diberikanlah kuesioner untuk dijawab oleh sejumlah reponden tersebut.

Hasil dari tabel perhitungan yang terdapat di atas dapat kita simpulkan bahwa hasil jawaban kuesioner dari 30 responden siswa kelas $X$ MAN 2 Banyuwangi, memiliki kecenderungan lebih nyaman menggunakan grip raket dengan berbahan towel (handuk), hal ini dapat kita lihat dari jumlah responden yang cenderung memilih towel sebanyak 18 responden dari jumlah keseluruhan responden dan menghasilkan persentase sebesar $55,78 \%$ dan jumlah siswa yang memilih grip karet sebanyak 12 siswa dari seluruh jumlah responden dan menghasilkan persentase sebesar 44 , $22 \%$.

Menurut pendapat Binus University (2018) grip handuk, nah grip jenis ini jarang dipakai para pemain dunia hanya Lin Dan saja, kelebihan grip ini adalah sangat empuk dan nyaman di pakai dan tangan tidak akan terluka karena sangat empuk dan sangat cocok sekali untuk pemain yang keringatnya berlebihan ditangannya pada saat bermain karena keringatnya akan di serap langsung oleh grip tersebut, tetapi memiliki beberpa kekurangan yaitu grip yang basah setelah kering akan kasar dan berbau tidak sedap, sebaiknya diberikan grip powder atau bedak agar grip tidak terlalu basah akan keringat. Pemilihan grip towel juga sangat dianjurkan bagi yang memiliki telapak tangan yang basah sehingga grip tidak akan terasa licin.

Grip karet kurang diminati oleh responden karena raket dengan grip karet ketika digunakan bisa terasa licin, terlebih lagi bagi yang memiliki tangan yang mudah berkeringat, licin akan sangat dirasakan ketika sedang melakukan pukulan - pukulan bulutangkis, tentu saja faktor ini akan menyebabkan rasa tidak nyaman ketika bermain bulutangkis. Pendapat ini sesuai dengan hasil kuesioner nomor 2 sebanyak 17 responden menyatakan ketika menggunakan grip karet tangan akan mudah berkeringat dan juga soal nomor 8 sebanyak 17 responden juga menyatakan ketika bermain bulutangkis dengan menggunakan grip karet tangan terasa licin.

Dapat kita ambil kesimpulan dengan melihat data di atas yaitu grip towel lebih nyaman digunakan dari pada 
grip karet, dimana grip towel memiliki beberapa kelebihan sesuai yang disampakain pendapat diatas salah satunya terasa empuk dan tidak licin saat digunakan, hal ini juga didukung dari jawaban responden pada kuesioner nomor 7 yang sudah diberikan kepada responden sebanyak 17 dari 30 responden menyatakan tidak merasakan licin ketika menggunakan grip towel. Ketika grip tidak terasa licin maka akan memudahkan dalam melakukan pukulanpukulan dalam bermain bulutangkis.

\section{KESIMPULAN}

Berdasarkan hasil penelitian dan pembahasan, penelitian ini menyimpulkan bahwa perbandingan tingkat kenyamanan penggunaan grip karet dan towel oleh siswa Madrasah Aliyah Negeri 2 Banyuwangi kelas $X$ tahun ajaran 2018/2019 adalah sebagai berikut, sebanyak 18 dari jumlah keseluruhan 30 responden, menyatakan lebih nyaman menggunakan grip towel, dengan menghasilkan persentase sebesar $55,78 \%$, dibandingkan dengan 12 responden yang menyatakan nyaman menggunakan grip karet dengan persentase sebesar $44,22 \%$. Jadi dapat kita simpulkan bahwa tingkat kenyamanan siswa dalam menggunakan grip karet dan towel, siswa lebih cenderung nyaman menggunakan grip towel.

\section{DAFTAR PUSTAKA}

Arnanda, R. D. (2017). Tingkat Pengetahuan Siswa tentang Permainan Bulutangkis Kelas $X$ SMK Koperasi Tahun Ajaran 2016/2017 Kota Yogyakarta. Yogyakarta: Universitas Negeri Yogyakarta.

Blog, P. (2016). Pengertian dan Definisi

Tujuan Pendidikan Menurut Undang - Undang dan Pakar Pendidikan (Online): http://www.pelangiblog.com/2016/ 07/tujuan-pendidikan-di-indonesiamenurut.html?m=1 (Diakses 9 April 2018)

Hade, J. (2018). Bagaimana Memilih Grip. (Online),Http://www.bulutangkis.co $\mathrm{m} / \mathrm{mod}$.php?mod=publisher\&viewa rticle\&artid $=105227 \quad$ (Diakses 9 April 2018)

Humas. (2018) Instrumen Penelitian Kuantitatif.

(Online) $\mathrm{Http}$ ://penalaranunm.org/instrumen -penelitian-kuantitatif/. (Diakses 20 April)

Illus, S. d. (2015). Studi Tentang Kenyamanan Pejalan Kaki Terhadap Pemanfaatan Trotoar Di Kota Pontianak. Studi Kasus Jalan Sultan AbdurRahman Pontianak, 2-3.

Ilmu, P. (2017). Sejarah, Pengertian, Teknik Permainan, dan Peraturan. (Online)

Http://www.Pojokllmu.com/bulutan gkis/. (Diakses 12 april 2018)

Iswadin, A. F. (2017). Pengaruh Latihan Kelincahan dan Keseimbangan Terhadap kemampuan Menggiring Bola Pemain Sepak Bola SSB Seyegen United Usia 13-14 Tahun. Yogyakarta: Universitas Negeri Yogyakarta.

Junanda, H. A. (2016). Kecepatan dan Akurasi Shuttlecock pada Jump Smash dengan Loncatan Vertikal dan Parabol Depan dalam Bulutangkis. Jurnal Terapan IImu Keolahragaan, 17-33.

Maulidi, A. (2016). Pengertian Kenyamanan. (Online) https://www.kanalinfo.web.id/2016/ 06/pengertian-kenyamanan.html. (Diakses 7 Mei 2018)

Prasetya, B. B. (2012). Manajemen Pembinaan Prestasi Cabang Olahraga Bulutangkis di Klub PB. Surya Baja Tulungagung. 
Surabaya: Universitas Negeri Surabaya.

Pujianto, A. (2012). Modifikasi Pegangan

Raket untuk Meningkatkan

Kemampuan Teknik Pegangan

Bulutangkis. Jurnal Media Umum

Keolahragaan Indonesia, 1-9.

Putra, R. P. (2017). Hubungan Antara Servis Pendek, Dropshot, Lob dan Smash Dengan Ketrampilan Bermain Bulutangkis Siswa Ekstrakulikuler SMP Negeri 1 Tempel. Yogyakarta: Universitas Negeri Yogyakarta.

R., B. R. (2014). Persepsi Pengunjung Taman Terhadap Tingkat Kenyamanan Taman-Taman di Kota Banjar Negara Sebagai Ruang Publik. Semarang: Universitas Negeri Semarang.

Ramdhan. (2017). Mengembalikan Kejayaan Raja Tunggal Bulutangkis Indonesia. Petuah Tan Joe Hok dan Rudy Hartono (Online)

Http://www.indosport.com/raket/20 17417/mengembalikan-kejayaanraja-tunggal-bulutangkisindonesia/petuah-tan-joe-hok-danrudy-hartono).(Diakses 15 April 2018)

Rini, Y. S. (2013). Pedidikan Hakekat, Tujuan, Dan Proses. Yogyakarta.

Sesar, D. R. (2018). Hubungan Koordinasi Mata Tangan dengan Ketepatan Pukulan Lob Bulutangkis Klub Jogjaraya Kota Gede . Yogyakarta: Universitas Negeri Yogyakarta.

Sugiyono. (2015). Metode Penelitian Pendidikan. Bandung: Alfabeta.

Trianto, M (2015) Metode Penelitian Menurut Sugiyono . (Online) (http://rayendar.blogspot.com/201 5/06/metode-penelitianmenurutsugiyono-2013.html?m=1) (Diakses 2 Juni 2018)
University, B. (2018). Grip karet vs Grip Handuk (Badminton). (Online) scdc.binus.ac.id/badminton/2018/0 4/grip-karet-vs-grip-handukbadminton (Diakses 14 September 2018) 